\title{
Comportamento dos preços dos insumos agrícolas da cana-de-açúcar: safra 2016/17
}

Agricultural inputs prices behavior of sugar cane: harvest 2016/17

\author{
Aline Bigaton*; Gustavo Bressan²; João Marcos Meneghel de Moraes³; Haroldo José Torres da \\ Silva ; João Henrique Mantellatto Rosa ${ }^{5}$
}

\begin{abstract}
${ }^{1}$ UNICAMP - Mestra em Planejamento de Sistemas Energéticos (Faculdade de Engenharia Mecânica) - Rua Alexandre Herculano 120, sala B12, Vila Monteiro - 13418-445 - Piracicaba, SP -, Brasil *Autor correspondente < alinebigaton@pecege.com>

${ }^{2}$ ESALQ/USP - Graduando em Administração - Rua Alexandre Herculano 120, sala B12, Vila Monteiro - 13418-445 - Piracicaba, SP - Brasil

3 ESALQ/USP - Bacharel em Engenharia Agronômica - Rua Alexandre Herculano 120, sala B12, Vila Monteiro - 13418-445 - Piracicaba, SP - Brasil ${ }^{4}$ ESALQ/USP - Doutorando em Economia Aplicada (Departamento de Economia, Administração e Sociologia) - Rua Alexandre Herculano 120, sala B12, Vila Monteiro - 13418-445 - Piracicaba, SP - Brasil

${ }_{5}^{5}$ ESALQ/USP - Doutor em Engenharia de Sistemas Agrícolas - Rua Alexandre Herculano 120, sala B12, Vila Monteiro - 13418-445 - Piracicaba, SP Brasil
\end{abstract}

\section{Resumo}

Esta publicação apresenta as variações de preços dos produtos utilizados como insumos agrícolas na produção de cana-de-açúcar nas principais regiões produtoras do estado de São Paulo, entre os meses de dezembro de 2016 e janeiro de 2016. As variações de preços mais expressivas foram representadas pela classe dos inseticidas, no painel de Barretos e pelos corretivos, no painel de Araçatuba. Apesar disso, a classe de fertilizantes também apresenta variações expressivas em todos os painéis, sendo que estes insumos foram os mais representativos na composição dos custos de produção. A representatividade dos custos com insumos para a produção da cultura com relação ao total recebido por hectare apresentou uma média próxima dos 14\%, sendo a região de Paulo de Faria a que apresenta maior representatividade $(25 \%)$.

Palavras-chave: insumos, preços, produção agrícola

\begin{abstract}
This publication presents the price variations of the products used as agricultural inputs in the production of sugarcane in the main producing regions of the state of São Paulo, between December 2016 and January 2016. The most significant price variations were represented by the class of insecticides, in the panel of Barretos and by the corrective ones, in the panel of Araçatuba. Nevertheless, the fertilizer class also presents significant variations in all panels, and these inputs are the most representative in the composition of production costs. The representativeness of input costs for crop production in relation to the total received per hectare showed an average around 14\%, with the region of Paulo de Faria being the most representative $(25 \%)$.
\end{abstract}

Keywords: inputs, prices, agricultural production

\section{Introdução}

Para expressar todo seu potencial produtivo, a cultura da cana-de-açúcar requer a utilização de diversos insumos agrícolas, tanto no plantio, quanto nos tratos culturais do canavial. Segundo dados do PECEGE (2016), os insumos representam um total que pode variar entre 13 a 16\% do custo operacional total, dependendo da região.

Um dos principais insumos são os fertilizantes, que apresentam uma relação estreita com a produtividade agrícola. Entre os vários insumos agrícolas, estes, em conjunto com a água, são os que mais contribuem para o aumento da produção (Isherwood, 2000).

Outro insumo muito utilizado na produção da cultura da cana são os herbicidas. A ocorrência de plantas daninhas na cultura provoca perdas sérias na produtividade, quando não controladas adequadamente, e, segundo Victoria Filho e Cristoffoleti (2004), para minimizar os efeitos negativos, o mais comum é utilizar o controle químico com a aplicação de herbicidas.

Ainda, segundo Loureiro $(2004)^{1}$, dentre os fatores que afetam o crescimento, desenvolvimento e produtividade da cultura da cana-de-açúcar, os insetospraga têm papel de destaque. Tanto na região Nordeste, quanto no Sudeste do Brasil, as cigarrinhas, por exemplo, representam um dos principais problemas fitossanitários da cultura, o que torna o uso dos inseticidas muito frequente.

Outro insumo de evidência para a produção agrícola é o diesel, o qual, além de aumentar os custos em função

\footnotetext{
${ }^{1}$ Loureiro, E. de S. 2004. Seleção e Avaliação de Campo de Isolados de Metarbizium anisopliae (Metsch.) Sorok. para o Controle da Cigarrinha-da-Raíz da Cana-de-Açúcar, Mahanarva fimbriolata (Stal, 1854) (Hemiptera: Cercopidae). 2004. 101 p. Tese (Doutorado) - Curso de Doutorado em Agronomia Área de Concentração em Proteção de Plantas, Faculdade de Ciências Agronômicas da Unesp - Campus de Botucatu, Botucatu - Sp, 2004. Disponível em: < https:// repositorio.unesp.br/bitstream/handle/11449/105421/loureiro_es_dr_botfca.pdf?sequence=1\&isAllowed=y $>$. Acesso em: 06 nov. 2017.
} 
da utilização como combustível para o maquinário, também aumenta os custos dos outros insumos de maneira indireta em função do frete.

Tendo em vista a importância da utilização desses inputs para a produção da cana-de-açúcar, o Programa de Educação Continuada em Economia e Gestão de Empresas [PECEGE/ESALQ/USP], em parceria com a Confederação da Agricultura e Pecuária do Brasil [CNA], desenvolve mensalmente uma pesquisa de mercado sobre os principais insumos agrícolas empregados na produção de cana-de-açúcar nas regiões mais representativas do Brasil, denominadas por "painéis", neste artigo foram consideradas apenas as regiões do estado de São Paulo. O período de coleta dos dados para os preços nos meses analisados foi entre a segunda quinzena do mês de análise e a primeira semana do mês posterior, sendo os produtos agrupados em classes de insumos: combustível (diesel), corretivos, fertilizantes, herbicidas e inseticidas.

Posteriormente, calculou-se os custos com insumos de cada região considerando as variações de preços observadas, cada produto apresenta um peso diferente nos cálculos, de acordo com sua representatividade em cada painel, conforme Tabela 1.

Tabela 1. Pesos das classes de insumos para cálculos de custos de produção de cana-de-açúcar dos painéis

\begin{tabular}{|c|c|c|c|c|c|}
\hline Painel & Combustível & Corretivos & Fertilizantes & Herbicidas & Inseticidas \\
\hline & & & -----'- & ------- & ------ \\
\hline Andradina-SP & 5,28 & 7,56 & 41,96 & 15,23 & 5,70 \\
\hline Araçatuba-SP & 14,95 & 8,27 & 35,91 & 10,50 & 13,42 \\
\hline Araraquara-SP & 7,41 & 9,80 & 40,06 & 13,54 & 10,64 \\
\hline Barretos-SP & 3,80 & 9,84 & 42,53 & 12,10 & 7,86 \\
\hline Guariba-SP & 4,62 & 7,93 & 47,40 & 12,01 & 10,40 \\
\hline Ituverava-SP & 3,44 & 14,65 & 38,55 & 10,36 & 12,16 \\
\hline
\end{tabular}

\section{Comportamento dos preços}

Os preços coletados ao longo do ano de 2016 foram considerados para esta análise, comparando-se os valores apresentados no mês de dezembro em relação ao mês de janeiro. A variação mais significativa foi representada pela classe dos inseticidas, no painel de Barretos ($32,90 \%$ ), sendo que a maior variação positiva de preços foi representada pela classe dos corretivos, no painel de Araçatuba $(11,80 \%)$, os valores podem ser observados na Tabela 2.
No painel de Barretos, o principal produto que influenciou os preços de inseticidas foi o Regent, o qual variou negativamente em 24,51\%. No painel de Araçatuba, o principal corretivo que influenciou a variação de preços dessa classe foi o calcário dolomítico, com variação positiva de $16,0 \%$.

Destacou-se também da Tabela 2 as variações representativas da classe dos fertilizantes, em todos os painéis de análise, que, em média, apresentou variação de $-22 \%$ de janeiro para dezembro.

Tabela 2. Variação de preços das classes de insumos agrícolas utilizados na produção de cana-de-açúcar - dezembro/2016 em relação a janeiro/2016

\begin{tabular}{|c|c|c|c|c|c|}
\hline Painel & Combustível & Corretivos & Fertilizantes & Herbicidas & Inseticidas \\
\hline & & & $\%$ & ------- & ---------------- \\
\hline Andradina-SP & $-1,40$ & 5,60 & $-18,50$ & $-10,80$ & $-29,70$ \\
\hline Araçatuba-SP & $-5,80$ & 11,80 & $-19,00$ & $-23,70$ & $-9,20$ \\
\hline Araraquara-SP & $-3,80$ & 5,90 & $-17,20$ & $-9,70$ & $-25,80$ \\
\hline Barretos-SP & 0,20 & 9,00 & $-28,20$ & $-11,60$ & $-32,90$ \\
\hline Guariba-SP & $-3,00$ & 8,40 & $-30,20$ & $-13,30$ & $-25,80$ \\
\hline Ituverava-SP & $-0,30$ & 8,60 & $-17,50$ & $-6,50$ & $-28,00$ \\
\hline Paulo de Faria-SP & $-1,90$ & 7,70 & $-30,80$ & $-20,60$ & $-5,40$ \\
\hline
\end{tabular}

Os preços de insumos tornaram-se importante instrumento na decisão de época de compra dos produtos. As variações dos preços da classe de fertilizantes foram analisadas para os painéis em questão, conforme Figura 1, a qual demostrou que as variações começam a ficar menores a partir do mês de setembro, ou seja, os preços começam a subir e a ficarem mais próximos do valor praticado no mês de janeiro. Segundo D'Aragone (2016), os fertilizantes agrícolas possuem um pico de compra entre os meses de abril a outubro, sendo a concentração neste período de $87,8 \%$ das compras anuais, com centralização de $24,1 \%$ em agosto, o maior acréscimo das compras ocorre com o início da safra. 


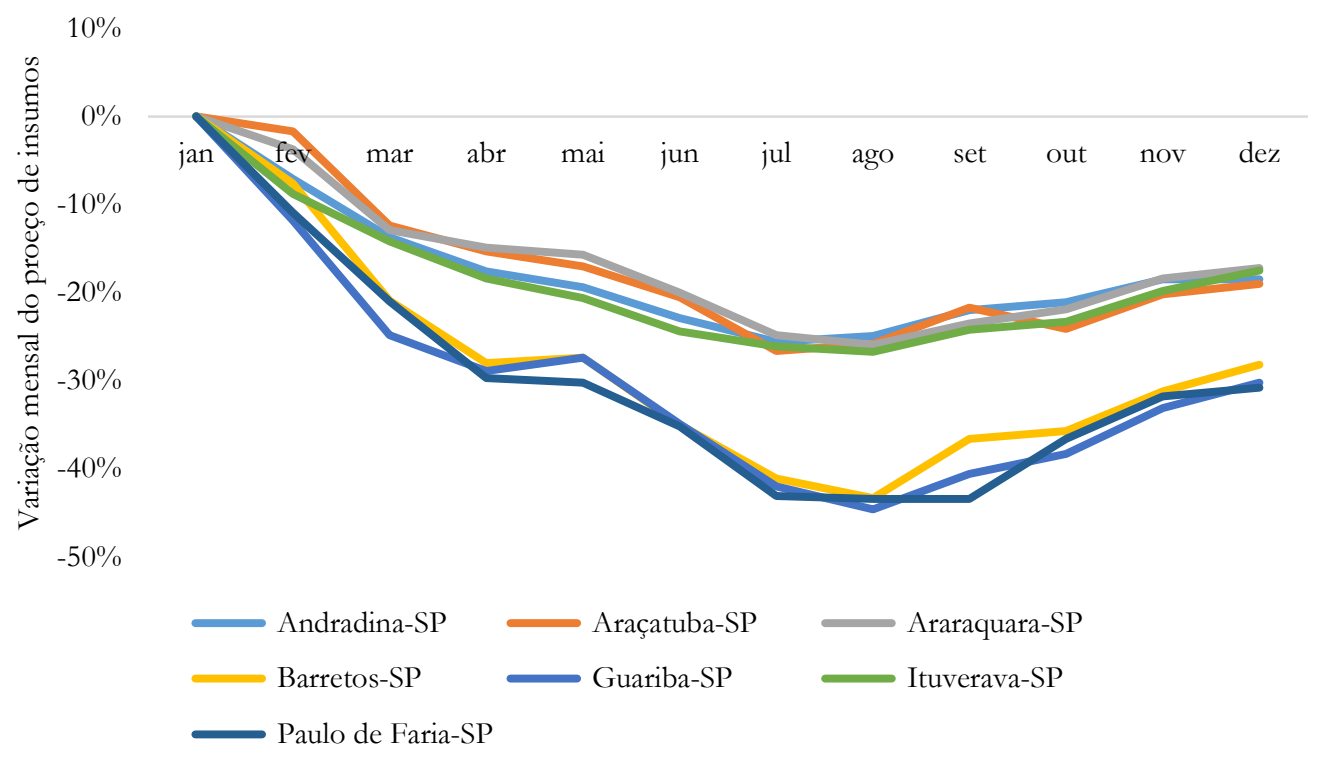

Figura 1. Variação mensal dos preços fertilizantes ao longo do ano de 2016

\section{Influência nos custos de produção}

Os pesos dos produtos dentro dos painéis de análise estão demonstrados na Figura 2. A partir destes dados, infere-se que a variação nos preços de fertilizantes possui

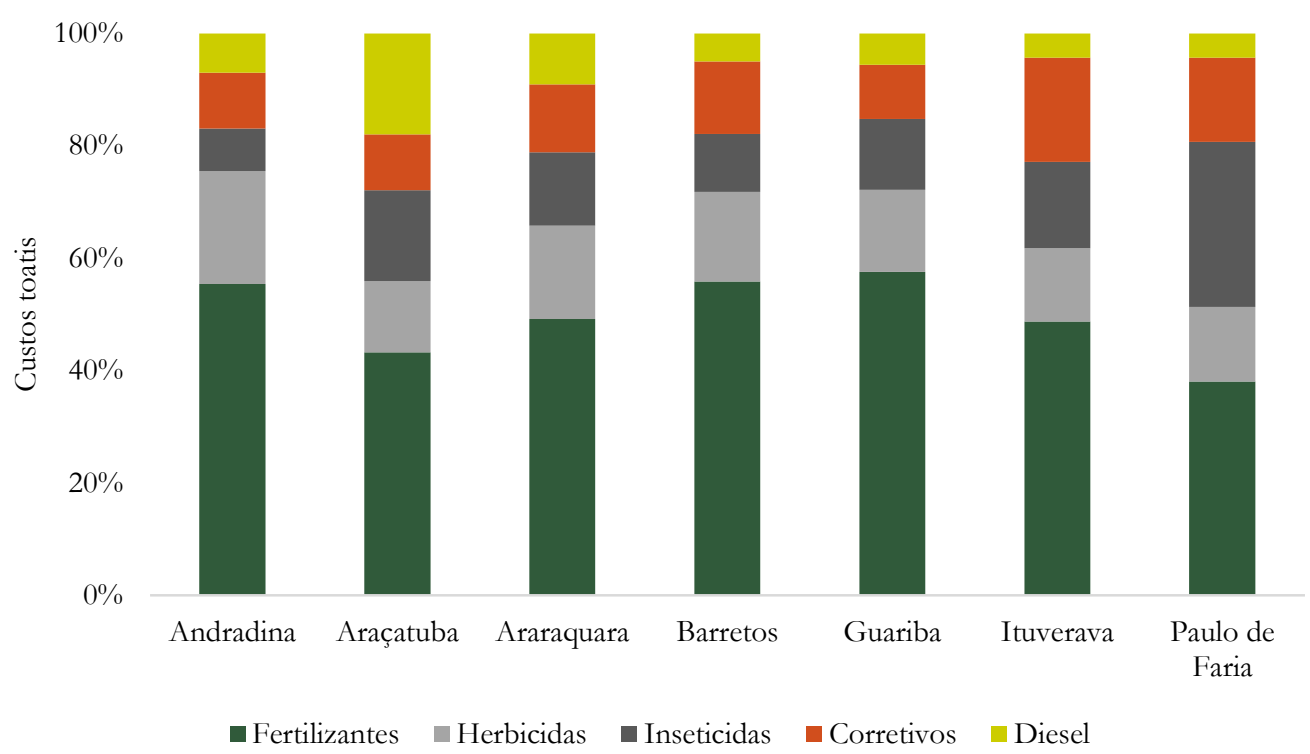

Figura 2. Pesos das classes de insumos nos custos totais com insumos

Os custos com insumos para a produção de cana-deaçúcar de cada painel foram calculados para os meses de janeiro e dezembro de 2016 (Tabela 3). Os painéis que apresentaram maior variação foram Ituverava-SP $(-6,1 \%)$ e Andradina-SP (-5,8\%). grande influência nos custos totais de produção de canade-açúcar, uma vez que esta classe apresentou representatividade próxima de $50 \%$ nos custos totais com insumos.

A partir dos dados de custos com insumos, comparou-se estes dispêndios com os valores recebidos pelos produtores de cana-de-açúcar por hectare, para os meses de janeiro e dezembro de 2016, conforme Figura 3. 
Tabela 3. Variação dos com insumos para a produção de cana-de-açúcar, no período de janeiro e dezembro de 2016

\begin{tabular}{|c|c|c|c|c|}
\hline Painel & $\begin{array}{c}\text { Variação nos } \\
\text { preços }\end{array}$ & $\begin{array}{c}\text { Custo dos insumos em } \\
\text { Janeiro/16 }\end{array}$ & $\begin{array}{c}\text { Custo dos insumos em } \\
\text { Dezembro/16 } \\
\end{array}$ & $\begin{array}{c}\text { Variação nos custos } \\
\text { com insumos }\end{array}$ \\
\hline & $\%$ & -------------------------- R\$ h & ------------------------------- & ---------- \% -------- \\
\hline Andradina-SP & $-6,0$ & $1.956,66$ & $1.843,11$ & $-5,8$ \\
\hline Araçatuba-SP & $-5,3$ & $2.177,33$ & $2.085,09$ & $-4,2$ \\
\hline Araraquara-SP & $-6,4$ & $1.763,94$ & $1.664,08$ & $-5,7$ \\
\hline Barretos-SP & $-11,1$ & $1.483,28$ & $1.413,48$ & $-4,7$ \\
\hline Guariba-SP & $-7,9$ & $1.675,68$ & $1.582,73$ & $-5,5$ \\
\hline Ituverava-SP & $-6,1$ & $1.864,47$ & $1.751,31$ & $-6,1$ \\
\hline Paulo de Faria-SP & $-9,8$ & $2.066,84$ & $2.036,67$ & $-1,5$ \\
\hline
\end{tabular}

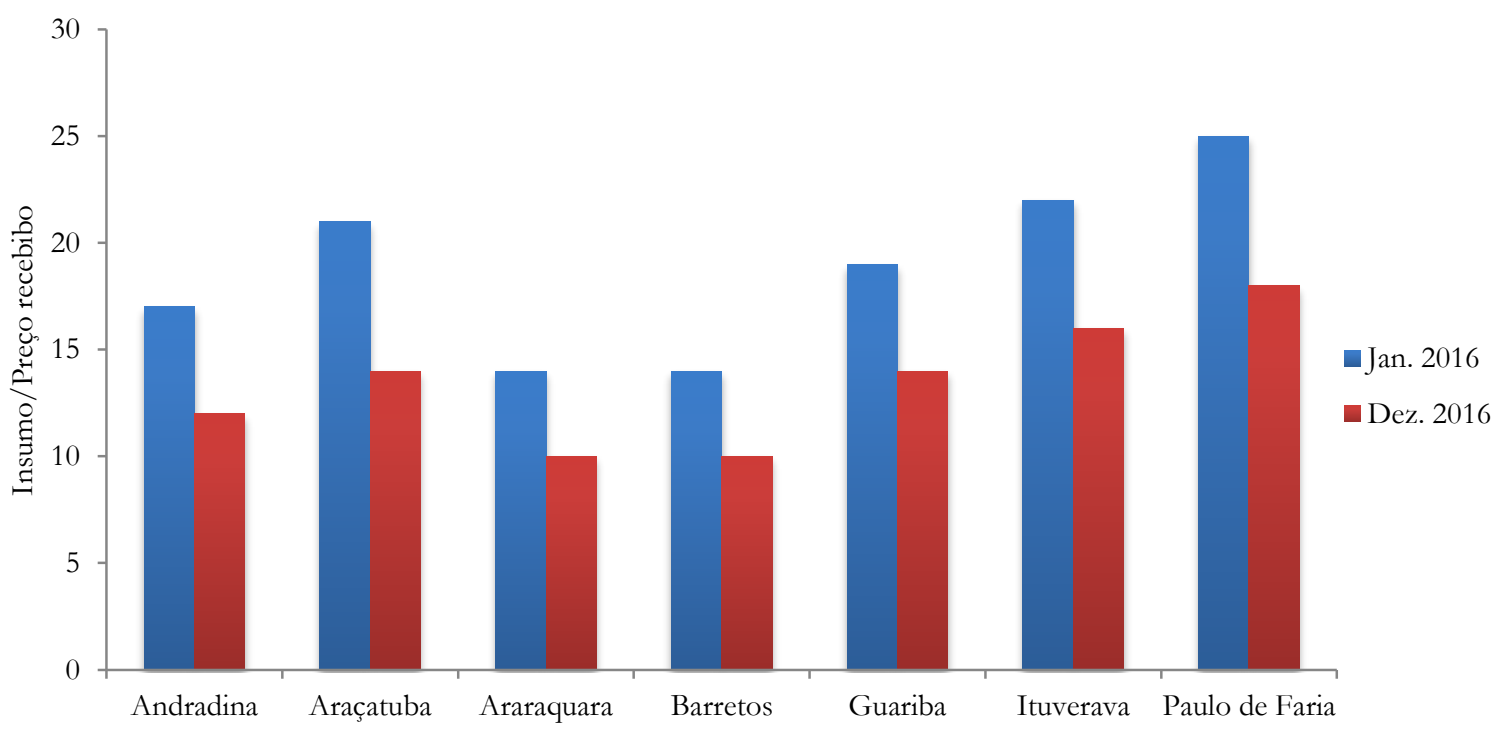

Figura 3. Representatividade dos insumos em relação ao preço total recebido pela cana, por hectare, no ano de 2016

O painel de Paulo de Faria foi o que apresentou maior representatividade dos custos com insumos com relação ao valor recebido pela cana por hectare, ou seja, do valor total recebido pela produção de cana em um hectare, aproximadamente $25 \%$ foi para cobrir gastos com insumos, no mês de janeiro de 2016. Já no mês de dezembro de 2016, essa porcentagem foi próxima dos $18 \%$. Os painéis que apresentaram menor representatividade dos insumos com relação ao valor recebido pela cana foram Araraquara e Barretos, com valores próximos de 14\% em janeiro de 2016 e $10 \%$ em dezembro do mesmo ano.

\section{Considerações finais}

A observação da variação de preços de insumos agrícolas é uma importante ferramenta para tomada de decisão do produtor de cana-de-açúcar, possibilitando melhoria da gestão e de resultados. Assim como ter conhecimento dos principais impactantes nos custos, através da análise dos produtos que causam maior influência nos dispêndios para a produção da cana-de- açúcar. Para os painéis citados, por exemplo, os fertilizantes são os que tem maior representatividade na cesta de insumos, variando nas regiões entre $32 \%$ a $48 \%$, aproximadamente.

Portanto, em decorrência de os insumos agrícolas apresentarem uma expressiva representatividade nos custos, destaca-se a acuidade de estudar o time certo de compras, com o intuito de diminuir os custos e consequentemente diminuir também a porcentagem da receita que é destinada para pagar esses produtos, fazendo assim com que aumente o ganho para o produtor.

\section{Referências}

D'Aragone, R.R.; Bigaton, A.; da Silva, H.J.T.; Marques, P.V. 2016. Comportamento de compra de insumos agrícolas dos fornecedores de cana-de-açúcar no estado de São Paulo. Revista iPecege 2(4): 83-95.. 
Isherwood, K.F. 200. Mineral Fertilizer Use and the Environment. International Fertilizer Industry Association Revised Edition. Paris, France.

Programa de Educação Continuada em Economia e Gestão de Empresas [PECEGE]. 2016. Custos de produção de cana-de-açúcar, açúcar, etanol e bioeletricidade no Brasil: fechamento da safra 2015/2016 e acompanhamento da safra 2016/2017. -
Relatório apresentado à Confederação da Agricultura e Pecuária do Brasil [CNA]. PECEGE, Universidade de São Paulo, Escola Superior de Agricultura "Luiz de Queiroz", Piracicaba, SP.

Victoria Filho, R; Jacob, C.P. 2004. Manejo de plantas daninhas e produtividade da cana. Visão Agrícola 1: 32-37. 